\title{
Uso do Git e Trello para Produção Colaborativa de um Material Didático em IATEX
}

\author{
Josenaldo Silva Júnior ${ }^{1}$, Antonio I. S. de Oliveira ${ }^{1}$, Giordano Rodrigues ${ }^{1}$ \\ ${ }^{1}$ Instituto Metrópole Digital - Universidade Federal do Rio Grande do Norte (UFRN) \\ Av. Sen. Salgado Filho, 3000 - Lagoa Nova, CEP: 59.078-970 - Natal - RN - Brazil \\ josenaldo@ufrn.edu.br, igoroliveiradimd.ufrn.br, giordanovofr@gmail.com
}

\begin{abstract}
Resumo. O presente artigo descreve um relato de experiência acerca do uso das ferramentas tecnológicas Git, Trello e $E T_{E} X$ para a produção de um material didático para a disciplina de Matemática Elementar (ME), que faz parte do curso de Bacharelado em Tecnologia da Informação da Universidade Federal do Rio Grande do Norte. Será explicada a integração entre as ferramentas, com ênfase no aspecto colaborativo de sua utilização. Com isso, pretende-se apresentar possiveis serventias dessas tecnologias em um contexto colaborativo de produção de textos de ensino.
\end{abstract}

\begin{abstract}
This paper describes an experience report on the use of the technological tools Git, Trello and LaTeX for the production of a didactic material for the discipline of Elementary Mathematics (ME), which is part of the Bachelor of Information Technology (BTI) course at the Federal University of Rio Grande do Norte. It will be explained how the integration between the tools took place, with emphasis on the collaborative aspect of their use. In this way, it is intended to present possible uses of these technologies in a collaborative context of production of teaching texts.
\end{abstract}

\section{Introdução}

A escolha de uma bibliografia apropriada é de suma importância para o processo de ensino aprendizagem. Quando não há uma bibliografia adequada que se encaixe nos objetivos de uma disciplina, o material apresentado pelo professor é muito importante para diminuir essa deficiência. Ademais, no que tange a uma abordagem mais rigorosa da Matemática, materiais escritos têm uma importância elevada para nortear o estudo. Nessa perspectiva, o desenvolvimento de um texto em forma de notas de aula foi um dos produtos propostos pelo projeto de pesquisa sobre práticas de ensino auxiliares aplicadas na disciplina de ME. Para tanto, escolheu-se o LTEX para escrever o texto, o Git, para controlar as versões das notas de aula, e o Trello, para organizar as demandas de cada participante.

A escolha do sistema de preparação de documentos $\mathrm{LT}_{\mathrm{E}} \mathrm{X}$ deveu-se, em maior parte, à versatilidade que a ferramenta proporciona na escrita de textos. Por meio do uso e da criação de comandos especiais, pode-se customizar documentos de forma rápida e prática, sem ter que se preocupar exacerbadamente com aspectos secundários como a aparência ([The LaTeX Project 1994]). Ademais, os comandos são facilmente reusáveis, o que viabiliza o seu compartilhamento para outros documentos, ainda que com diferentes autores. Isso favorece, também, a produção colaborativa de textos, considerando que cada 
VIII Congresso Brasileiro de Informática na Educação (CBIE 2019)

Anais do XXV Workshop de Informática na Escola (WIE 2019)

autor pode ser responsabilizado para uma seção específica do texto, mas podendo usar os mesmos comandos que os outros colaboradores.

O caráter dinâmico da produção de textos é amplificado na presença de vários autores. As revisões de conteúdo passam a ser mais frequentes, de forma que, por vezes, faz-se necessário voltar a versões anteriores do texto. E, com base nas alternativas propostas por [Henningsen 2007], foi decidido usar um sistema de controle de versões e, segundo [Ram 2013], a ferramenta Git se mostrou crucial para o versionamento de um documento produzido em LTEX.

Uma das funcionalidades do Git mais úteis na escrita das notas são as branches, ou ramos de desenvolvimento. Elas servem para manter vários fluxos de desenvolvimento de um produto paralelamente, de tal maneira que cada colaborador pode alterar arquivos independentemente dos outros. Outra funcionalidade bastante utilizada foi a merge, que permite juntar os trabalhos de branches, sincronizando, assim, os progressos realizados.

O componente colaborativo no desenvolvimento de qualquer produto traz, consigo, uma maior necessidade de gerenciamento do processo. Por isso, utilizou-se a aplicação Trello, que serve, de modo geral, para o gerenciamento de tarefas como atesta [STOPA e RACHID 2019]. Na aplicação, cada tarefa corresponde a um cartão. Os cartões, por sua vez, podem ser agrupados em listas. É comum que, na prática, as listas sejam usadas como abstrações para o tempo de vida das tarefas associadas ao projeto, por exemplo: em análise, em andamento e finalizadas. Finalmente, existem os quadros, nos quais podem ser colocadas várias listas logicamente relacionadas. Quando o projeto gerenciado é pequeno, um quadro apenas costuma ser suficiente para agrupar todas as listas e tarefas criadas.

\section{Métodos}

O processo geral de escrita das notas de aula usou, como estratégia principal, o SCRUM, que é um método ágil caracterizado pelo desenvolvimento iterativo e incremental de um produto de software ([Schwaber 2004]). De forma contínua, novas versões das notas de aula eram disponibilizadas, cada uma contendo novos conteúdos ou melhorias do que havia sido escrito até então. O SCRUM foi investigado como prática de desenvolvimento ágil de recursos educacionais abertos por [Arimoto e Barbosa 2012], sendo julgado adequado para essa finalidade. Já [Souza et al. 2018] relataram sua experiência com a implementação de um recurso tecnológico baseado no SCRUM, na qual utilizaram, também, o Trello.

Com relação às ferramentas tecnológicas, aborda-se, primeiro, o $\mathrm{LT}_{\mathrm{E}} \mathrm{X}$. Esse sistema já vinha sendo usado desde o começo do processo de preparação das notas, em agosto de 2018. Com relação ao aspecto colaborativo do uso da ferramenta, foram criados comandos que todos os participantes que viessem a escrever partes do texto deveriam utilizar. Além disso, definiram-se padrões para inserir itens no texto das notas, tais quais equações e imagens.

Ainda no período de agosto de 2018, apenas um dos participantes redigia, de fato, o material. Dessa forma, o Git, que também permeava o desenvolvimento desde então, servia como uma ferramenta de versionamento. Também pelo fato de haver apenas um envolvido direto na elaboração das notas, era utilizada somente uma branch no Git; a saber, a master. 
VIII Congresso Brasileiro de Informática na Educação (CBIE 2019)

Anais do XXV Workshop de Informática na Escola (WIE 2019)

Em janeiro de 2019, outro participante ingressou no projeto, na parte de produção do texto. Com isso, surgiu a necessidade de uma maior organização dos trabalhos realizados, de forma a permitir que todos os componentes pudessem trabalhar com autonomia. Assim, passou-se a utilizar várias branches no Git. A já existente master foi destinada às versões finalizadas do texto. Criou-se, então, a development, na qual eram colocados os textos que compunham o protótipo da versão atual das notas e os que não haviam sido aprovados. Finalmente, criou-se, também, a tmp, local de armazenamento de arquivos temporários a serem futuramente utilizados. Na Figura 1, são mostradas as branches. Ademais, essa arquiteturação aumentou a complexidade do versionamento do produto, $o$

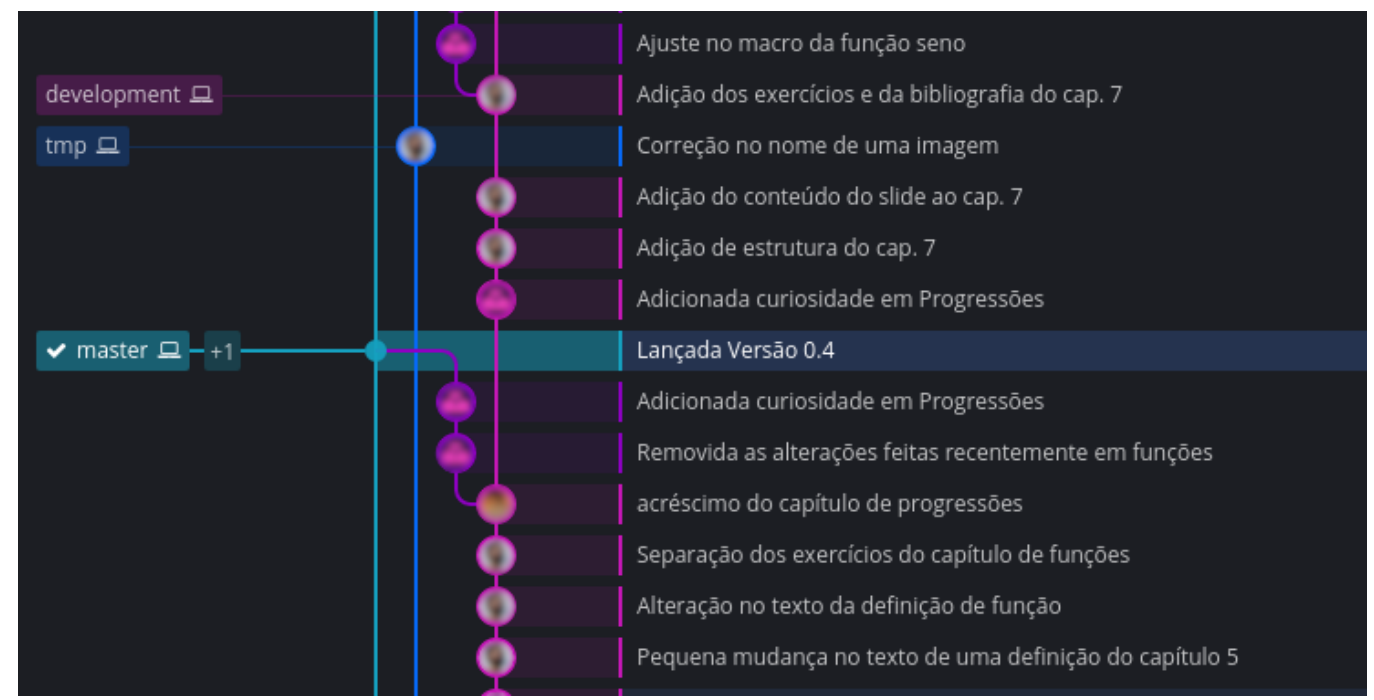

Figura 1. Ramos de desenvolvimento das notas de aula.

que motivou o emprego da ferramenta GitKraken, uma interface gráfica para o sistema Git. A Figura 1 é um screenshot dessa ferramenta.

No mês de fevereiro, perceberam-se dificuldades de gerenciamento dos afazeres e questões relacionadas ao projeto decorrentes do seu tamanho e complexidade. Para melhor dividir e atribuir tarefas aos componentes, começou-se a utilizar a aplicação Trello. Na Figura 2, é exibido um exemplo de utilização da ferramenta no projeto.

Criou-se, no Trello, um quadro para cada capítulo das notas de aula. Cada um deles possui, pelo menos, as listas Sugestões, Discussões, Pendências, Em Andamento, Em Análise e Finalizados. Ademais, também foi criado um quadro para questões pertinentes a todos os capítulos, que é o ilustrado na Figura 2. Os quadros vêm contribuindo para a organização do projeto e a documentação de todas as questões encontradas no seu desenvolvimento. Nas suas listas, são inseridos cartões, que correspondem, cada um, a uma tarefa ou preocupação a respeito das notas. Assim, é possível ter controle absoluto sobre o que foi e o que está sendo feito no decorrer da elaboração das notas.

\section{Resultados e Discussão}

Como principal fruto da metodologia do projeto, destaca-se o documento das notas de aula. À medida que o texto ia sendo escrito, disponibilizavam-se novas versões do documento para os alunos de ME. Mesmo que o uso do material não fosse estritamente 
VIII Congresso Brasileiro de Informática na Educação (CBIE 2019)

Anais do XXV Workshop de Informática na Escola (WIE 2019)

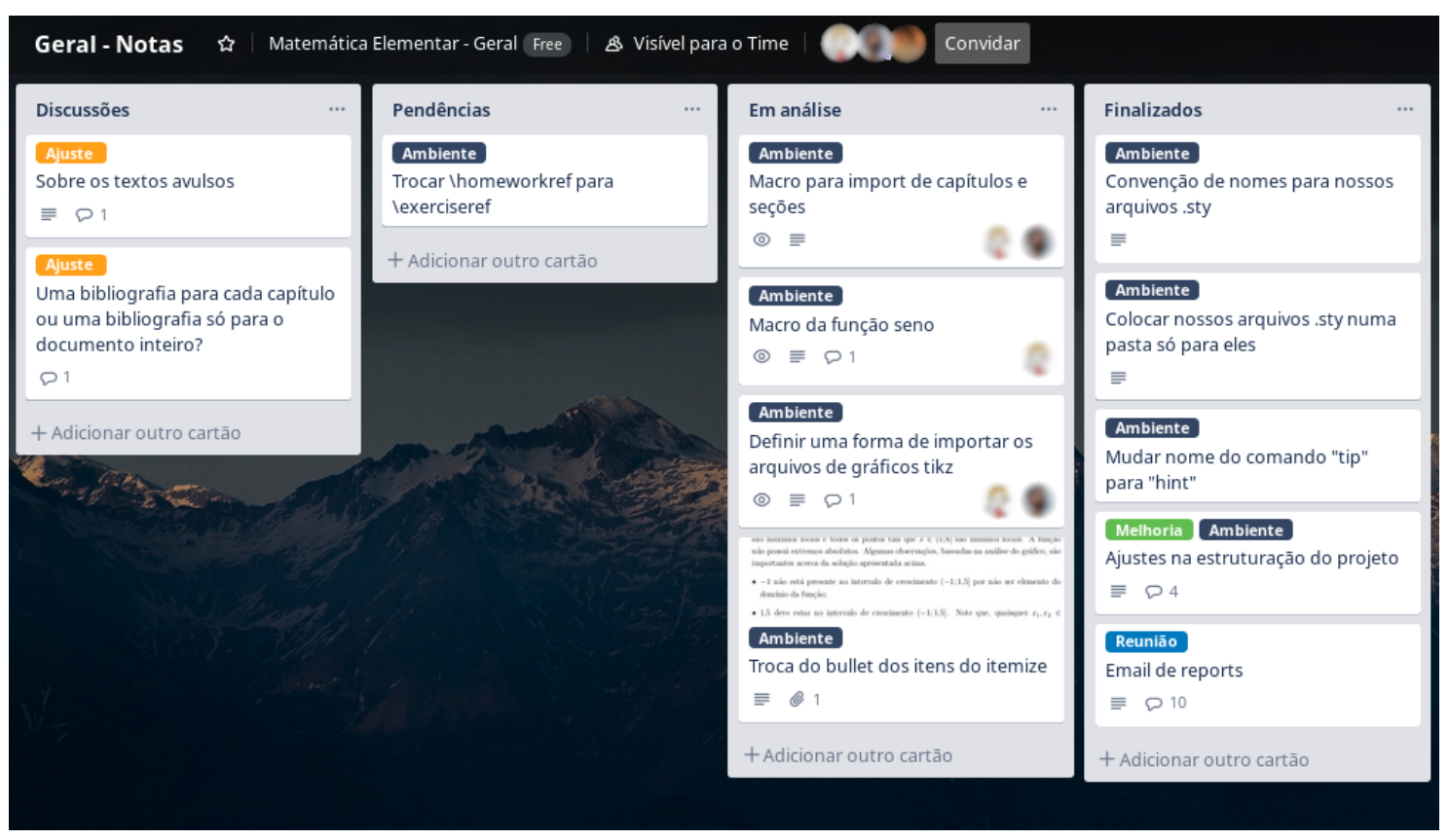

Figura 2. Exemplo de utilização do Trello.

obrigatório, os alunos reconheciam, por meio de relatos, os benefícios para seu estudo advindo das notas, e frequentemente questionavam os colaboradores do projeto acerca do andamento de novas versões.

Em termos de códigos-fonte em $\mathrm{LT}_{\mathrm{E}} \mathrm{X}$, o que foi produzido está contido em vários arquivos, favorecendo a colaboração de vários autores. Além disso, possíveis novos colaboradores podem ser alocados para partes específicas do projeto, de maneira a poderem começar a contribuir com textos sem que precisem analisar tudo o que foi feito anteriormente. Os comandos desenvolvidos, por sua vez, abstraem preocupações iniciais de caráter mais técnico.

\section{Conclusão}

Levando em conta o caráter preliminar do que foi desenvolvido no projeto, conclui-se que o objetivo inicial, que consistia em elaborar uma primeira versão das notas, foi atingido. Considera-se, também, que as ferramentas utilizadas contribuíram para o trabalho colaborativo dos componentes do projeto, tendo em vista que todos puderam trabalhar de forma autônoma e, quando necessário, integrar-se aos outros em eventuais discussões ou resolução de problemas específicos.

Como proposta para o futuro, pretende-se elaborar e ministrar minicursos de capacitação nas diversas ferramentas utilizadas no projeto. Destarte, a inclusão de novos participantes torna-se mais eficiente, tendo em vista que a divisão de atribuições faz, naturalmente, com que conhecimentos específicos das ferramentas se confinem aos colaboradores para os quais elas foram úteis. Além disso, almeja-se que os minicursos capacitem, também, quaisquer pessoas envolvidas com a produção colaborativa de textos, de forma a difundir as ferramentas usadas.

Dados os resultados satisfatórios da metodologia empregada, planeja-se estendêla a outros projetos futuros. Em particular, ela será adotada no desenvolvimento de um 
VIII Congresso Brasileiro de Informática na Educação (CBIE 2019)

Anais do XXV Workshop de Informática na Escola (WIE 2019)

solucionário dos exercícios e problemas contidos nas notas de aula. Tal solucionário terá a finalidade de ajudar os monitores da disciplina de ME a sanar dúvidas dos alunos, servindo como objeto de ensino auxiliar.

\section{Referências}

Arimoto, M. M. e Barbosa, E. (2012). Um conjunto preliminar de práticas para o desenvolvimento Ágil de recursos educacionais abertos. Anais dos Workshops do Congresso Brasileiro de Informática na Educação, 1(1).

Henningsen, A. (2007). Tools for collaborative writing of scientific latex documents. The PracTEX Journal, 3(1).

Ram, K. (2013). Git can facilitate greater reproducibility and increased transparency in science. Source code for biology and medicine, 8(1):7.

Schwaber, K. (2004). Agile Project Management with Scrum. Developer Best Practices. Microsoft Press, 1 edition.

Souza, D., Vergottini, V., e Bernini, D. (2018). Educação dos tempos modernos através da aprendizagem colaborativa: uma abordagem sobre eduscrum. Brazilian Symposium on Computers in Education (Simpósio Brasileiro de Informática na Educação - SBIE), 29(1):51.

STOPA, G. R. e RACHID, C. L. (2019). Scrum: Metodologia ágil como ferramenta de gerenciamento de projetos. CES Revista, 33(1):302-323.

The LaTeX Project (1994). An introduction to latex. Disponível em: https: / / www . latex-project.org/about/. Acesso em: 07 de jul. de 2019. 